\title{
"Olhares": reflexões sobre uma Experiência com Mulheres Moradoras de Residências Inclusivas
}

\author{
Aline Maria de Sordi ${ }^{1}$ (D) , Ana Paula Müller de Andrade² (D), \\ Fernanda Ribeiro Feola ${ }^{3}$ (D)
}

\begin{abstract}
Resumo: Este artigo apresenta e discute uma experiência produzida com mulheres moradoras de duas residências inclusivas, enfatizando a atuação da psicologia no âmbito da proteção social especial por meio de uma intervenção fotográfica. As atividades foram desenvolvidas no ano de 2019, como parte da experiência de estágio profissionalizante, e tiveram como eixos norteadores a produção de subjetividade e a desinstitucionalização, com vistas a ampliação das possibilidades de inserção social às moradoras e a reafirmação do compromisso ético-político da psicologia com a superação de processos de exclusão e estigmatização de grupos marginalizados. Os dados analisados constavam nos diários de campo elaborados ao longo do diagnóstico institucional, do planejamento, do desenvolvimento e da avaliação das atividades desenvolvidas. Consideramos que o estágio foi um dispositivo potente em nosso processo de formação e, além disso, a intervenção fotográfica produziu entre nós e as mulheres moradoras a ampliação das possibilidades de produção subjetiva e territórios existenciais.
\end{abstract}

Palavras-chave: assistência social, residências inclusivas, mulheres, subjetividade, desinstitucionalização

\section{"Olhares": Reflections about an Experience with Woman Resident in Inclusive Residences}

\begin{abstract}
This article shows and discusses an experience produced with resident women in two inclusive residences, emphasizing the psychology role within special social protection through_a_photographic intervention. The activities were developed in the year of 2019, as part of a professional internship, and had as guiding elements the production of subjectivity and the deinstitutionalization, in order to expand the possibilities of social insertion of the inclusive home residents and the reaffirmation of political ethics obligation of psychology with the overcoming of exclusions and stigmatization of marginalized groups. The analyzed data were included in the field notes elaborated throughout the institutional diagnosis, planning, development and the evaluation of the activities developed. We consider that the intership was a potential device in our formation process and, furthermore, the photographic intervention produced between us and the inclusive home resident women the expansion of possibilities of subjective production and existential territories.
\end{abstract}

Keywords: social assistence, inclusive residences, women, subjective, deinstitutionalization

1 Residente em Saúde da família- ESP, São José dos Pinhais-PR- Brasil.E-mail: alinedesordi8@gmail.com

2 Doutora em Ciências Humanas, Unicentro, Irati-PR, Brasil. E-mail: anamullerdeandrade@gmail.com

3 Residente em Saúde Mental Coletiva-UFRGS, Porto Alegre-RS, Brasil. E-mail: fernandaribeirofeola123@gmail.com

Submetido em: 09/12/2020. Primeira decisão editorial: 13/05/2021. Aceito em: 27/05/2021. 


\section{Introdução}

Este artigo apresenta e discute uma experiência produzida de março a novembro de 2019, em duas residências inclusivas, como parte de um estágio profissionalizante do curso de psicologia. As residências inclusivas compõem os serviços de acolhimento institucional para jovens e adultos com deficiências no âmbito da assistência social. Do encontro com a equipe e com as mulheres moradoras, produzimos várias ações, dentre elas uma intervenção fotográfica. Neste trabalho discutiremos tal intervenção, articulando-a com as demais ações e com os processos de subjetivação mútuos, ou seja, de coprodução entre sujeitos - mulheres moradoras e estagiárias em formação.

Partimos, aqui, de uma psicologia implicada, ética e politicamente, com práticas de produção de vida, de reconhecimento da multiplicidade de formas de existência, aliadas à luta antimanicomial, aos processos de desinstitucionalização, à proteção social, à garantia de direitos e ao combate às violências de gênero, raciais e às desigualdades sociais. É ao lado dessas e de outras práticas que propomos relatar e discutir essa experiência de estágio.

Os estágios em psicologia são regulamentados a partir da Lei Federal № 11.788, de 25 de setembro de 2008, podendo ocorrer em diversas instituições, com supervisão institucional e supervisão de campo. Além disso, a Lei 4.119, de 1962, que dispõe sobre os cursos e formação de psicologia e regulamenta a profissão de psicólogos/ as, afirma que os/as mesmos/as devem buscar uma formação profissional polivalente com diferentes ênfases.

A inserção da psicologia no campo das políticas públicas se incrementou com a promulgação da Constituição Federal em 1988, quando, então, a assistência social em conjunto com a saúde e a previdência social, conformaram o tripé da seguridade social. A afirmação da assistência social enquanto política de Estado se deu por meio da regulamentação da Lei Orgânica da Assistência Social (LOAS) em 1993 e as políticas adjacentes a ela, tais como a Política Nacional de Assistência Social (PNAS), aprovada em 1998, e a implementação do Sistema Único de Assistência Social (SUAS), em 2005.

O trabalho na assistência social, outrora ocupado majoritariamente por assistentes sociais, passou a comportar outras áreas de conhecimento, entre elas a psicologia (Knevitz, 2016). Corrobora com tal argumento a Resolução no 17, de 20 de junho de 2011, que ratifica a equipe multidisciplinar definida pela Norma Operacional Básica - SUAS e obriga a inserção da psicologia em todos os níveis de complexidade da proteção social. Tal inserção convocou as/os profissionais da psicologia a atuar de forma ampla, de modo a construir respostas às complexas demandas exigidas pelos contextos em que se inseriram.

No caso das residências inclusivas, esse modo de atuação é uma necessidade e um desafio cotidiano, pois se trata de um território híbrido, ou seja, uma casa - serviço -, em constante invenção, visto que está a todo instante modulando-se e modulando as práticas ali construídas. Em última instância, consideramos que o "alvo" da política de assistência social é a vida e sua produção pelos sujeitos.

E a vida que é produzida no território, no espaço de produção da vida, das relações que estão em movimento, assim como adentra o espaço geográfico, histórico, cultural, social e econômico, sendo histórica e coletivamente construído e constituído, é o objeto da Política de Assistência Social, em todas as suas peculiaridades (Motta \& Scarparo, 2013, p. 237).

As residências inclusivas são serviços que compõem o acolhimento institucional da proteção social especial de alta complexidade do SUAS. Acolhem pessoas entre 18 e 59 anos, que possuem alguma deficiência e que não possuem condições de autossustentabilidade e retaguarda familiar ou que estejam em processo de desligamento de instituições de longa permanência (Ministério do Desenvolvimento Social e Combate à Fome, 2014). As residências inclusivas podem ser municipais ou regionalizadas.

A organização e funcionamento das mesmas são orientados pelo Estatuto da Pessoa com 
Deficiência (Lei n. 13.146, 2015) e pelo Programa Viver Sem Limites (Secretaria dos Direitos Humanos e Secretaria Nacional de Promoção dos Direitos da Pessoa com Deficiência, 2013), tendo como propósito "romper com a prática do isolamento, de mudança do paradigma de estruturação de serviços de acolhimento para pessoas com deficiência em áreas afastadas ou que não favoreçam o convívio comunitário" (MDSCF, 2014, p. 09). A proteção social nelas ofertada deve, então, ser pautada em práticas que visem a inserção comunitária.

Ante o exposto, ressaltamos que a experiência de estágio aqui apresentada e discutida foi produzida a partir do encontro entre a universidade e o serviço, e entre nós - estagiárias e as mulheres moradoras, tendo como amparo teórico, dentre outras, as contribuições de Michel Foucault (2004), Gilles Deleuze e Felix Guattari (1995) e Félix Guattari e Suely Rolnik (1996).

Esta perspectiva teórica nos permitiu pensar que a produção de subjetividade se dá a partir de processos constantes entre os sujeitos e as práticas discursivas. Conforme proposto por Guattari e Rolnik (1996), a produção de subjetividade se dá de forma maquínica, ela pode ser agenciada tanto com processos capitalísticos quanto com processos de singularização. A produção de subjetividade, assim entendida, constitui o que os autores denominam como um território existencial, produtor e produto de modos de vida, de se relacionar, de consumir, dentre outros. O território, nesse sentido, está relacionado ao vivido e abrange um sistema no qual o sujeito se sente "em casa". Esse sistema permite processos de territorialização, bem como de desterritorialização e reterritorialização constante, conforme as relações produzidas pelos sujeitos.

Para Deleuze e Guattari (1995), o território é antes de tudo um lugar de passagem, aberto e múltiplo. Como será apresentado no texto, trata-se de um território que pode ser objetivo, subjetivo e passível de transformação, ou seja, pode ser desterritorializado e reterritorializado. A reterritorialização diz respeito a uma nova territorialidade.

Como discutiremos adiante, a experiência produzida no estágio, em especial a intervenção fotográfica, possibilitou a produção de processos de subjetivação singularizados bem como de desterritorialização e reterritorialização, de desinstitucionalização entre as psicólogas em formação e as mulheres moradoras das residências inclusivas e, quiçá, entre a universidade e o campo mais amplo da assistência social onde as residências inclusivas estavam inseridas.

\section{Caminho Metodológico}

Trata-se de relato e discussão de uma experiência produzida como parte de um estágio profissionalizante de psicologia no âmbito do SUAS, realizado em duas residências inclusivas. O estágio foi produzido com as mulheres moradoras e a equipe de trabalhadoras/es de tais residências. As atividades ocorreram de março a novembro de 2019, com encontros semanais de quatro horas cada e, dentre outras ações, foi realizada uma intervenção fotográfica. A escolha de apresentar e discutir esta intervenção fotográfica decorreu da densidade analítica proporcionada pela mesma.

Oconjunto dos dados analisados foi composto pelos diários de campo elaborados ao longo do início, desenvolvimento e finalização das atividades. Os diários foram elaborados semanalmente por meio de uma escrita implicada (Hess, 2006), produzindo o que Medrado et al. (2014) denominaram como "arquivos vivos".

A análise foi realizada a partir da literatura que embasou a intervenção e resultou em um eixo central de discussão, qual seja, a produção de subjetividade no processo de fotografar a cidade. As análises e discussões foram construídas por meio de encontros entre as autoras, e entre elas e os materiais empíricos e bibliográficos disponíveis. Os nomes das mulheres moradoras apresentados ao longo do texto são fictícios, a fim de respeitar o anonimato delas.

\section{Caracterização do Campo}

A experiência foi produzida em duas residências inclusivas e regionalizadas, que contavam, na época, com 13 moradoras com idades 
que variavam de 23 a 57 anos, 16 cuidadoras, um motorista e uma equipe técnica composta por uma psicóloga, uma assistente social e um coordenador do serviço, também psicólogo. O serviço passou a ser campo de estágio profissionalizante do curso de Psicologia no ano anterior à experiência aqui apresentada e discutida.

A equipe técnica das residências inclusivas possuía um escritório de trabalho situado na sede da Secretaria Municipal de Assistência Social. Era nesse local que ficavam guardados alguns materiais de uso da equipe e das moradoras. Conforme observamos, no cotidiano de trabalho da equipe não havia um cronograma fixo de tarefas diárias e algumas atividades surgiam como demandas espontâneas direc3ionadas à equipe técnica ao longo dos dias. Entendemos que a proteção social executada na alta complexidade do SUAS muitas vezes requer invenções cotidianas que extrapolam rotinas devido às urgências características da mesma.

No entanto, como percebemos, algumas atividades eram distribuídas durante os dias da semana, à exemplo das segundas-feiras, quando a psicóloga e a assistente social separavam a medicação a ser administrada às moradoras durante a semana, e das visitas semanais realizadas pela equipe às casas com o intuito de acompanhar as moradoras, levar algum material que estas ou as cuidadoras precisassem e/ou fazer acompanhamento de compras, quando se fazia necessário. $\mathrm{Na}$ intenção de organizar tais atividades, a equipe técnica havia produzido um Plano de Organização do Cotidiano. Nele foi possível perceber que as atividades da psicóloga e da assistente social se assemelhavam.

Com relação às cuidadoras e ao motorista, acompanhamos um processo de formação sobre os cuidados-ofertados às moradoras bem como sobre o planejamento e a gestão dos processos de trabalho desenvolvidos nas residências.

Quando a experiência foi produzida, as moradoras tinham acesso à diversas atividades visando à reinserção social, vez que em sua maioria eram egressas de instituições de longa permanência de tipo manicomial. A maioria delas frequentava a escola, o Centro de Atenção Psicossocial, bem como realizavam outras atividades como cursos de artesanato, psicoterapia e academia de ginástica. As atividades pagas eram custeadas com o Benefício de Prestação Continuada (BPC) que recebiam.

\section{A Coprodução da Experiência: Primeiras Aproximações}

A psicologia, enquanto ciência e profissão, tem envidado esforços importantes para a consolidação de políticas públicas de caráter social, cumprindo com o compromisso ético-político assumido pela categoria de superar práticas excludentes e de violência. A partir de diferentes perspectivas epistemológicas, têm buscado produzir saberes e práticas capazes de gerar transformações em instituições situadas sócio-historicamente, tais como aquelas ligadas aos manicômios de todo tipo. No âmbito da formação, os esforços têm se intensificado por meio da revisão crítica dos currículos e da ampliação dos campos de estágio e sua articulação com as demandas locais, regionais e nacionais.

Para a construção da experiência aqui apresentada e discutida, fizemos um primeiro momento de aproximação com a equipe técnica, as cuidadoras, o motorista e as mulheres moradoras das residências, através de visitas às casas e ao escritório de trabalho. As visitas iniciais nas casas se configuraram como momentos de conversa e de aproximações com as mulheres moradoras e as cuidadoras, atentando para a complexidade daquelas casas-serviços. Aos poucos, buscamos interagir e conhecê-las em um processo de análise das demandas (Baremblitt, 1996) que iam surgindo ao longo dos encontros semanais e que eram compartilhadas nas supervisões acadêmicas semanais.

Destacamos, aqui, as demandas relacionadas às deficiências e aos transtornos mentais das moradoras, que nos interpelaram vigorosamente. Tais demandas exigiram que produzíssemos modos de atuação e comunicação diversos em nossas interlocuções. Como duas mulheres moradoras eram surdas, por exemplo, nossa forma usual de comunicação precisou ser adaptada, visto que não sabíamos a Língua Brasileira de Sinais - LIBRAS. Assim, com uma delas nos comunicávamos através 
da escrita em um caderno e/ou fazíamos gestos para que pudéssemos nos entender. Com a outra moradora, a comunicação era mais limitada, pois ela não sabia ler e escrever e sabia pouco a LIBRAS. Ao nos comunicarmos com ela, fazíamos alguns gestos e nem sempre sabíamos ao certo se nos compreendíamos. Entretanto, entendíamos que alguma comunicação se produzia em nossos encontros e tentativas de interlocução.

No percurso do estágio, foram muitas as situações que nos causaram estranhamentos, desconfortos e até mesmo medo. As deficiências e os transtornos mentais nos impactavam e diante desses impactos apostamos na produção de novas possibilidades para a experiência do estágio. Nesse processo, tomamos as deficiências como narrativas culturalmente fabricadas de corpos que perpassam diferentes aspectos da cultura (Gomes et al., 2019). Em geral, as deficiências se materializam em corpos que fogem à norma imposta pela sociedade e, por isso, são passíveis de diversos tipos de preconceitos, exclusão social e afetos. Assim, buscamos situar as moradoras enquanto sujeitos singulares, através de suas histórias de vida, e entender como, a partir destas, elas foram se produzindo subjetivamente. Fizemos esse exercício sobre nós mesmas com apoio das supervisoras de campo e acadêmica.

O medo foi um afeto que se produziu de modo intenso em alguns momentos. Para além dos temores comuns ante ao desconhecido, uma situação em especial produziu o medo intenso. Em um dos dias de estágio, e não mais que este, uma das moradoras ficou muito agitada e agrediu uma cuidadora com uma cadeira. Nossa primeira reação foi esquivar-nos da situação. Contudo, após o episódio, à medida que fomos nos reaproximando da moradora e compreendendo de modo mais ampliado a violência que havíamos presenciado, o medo foi sendo desconstruído.

Ante esse e outros afetos e impactos que marcavam nossos encontros e aproximações com as mulheres moradoras, tomamos o conceito de "atletismo afetivo", apresentado por Lancetti (2015), como um operador importante. Para o autor, o "atletismo afetivo" nos remete ao corpo do terapeuta, pois "ele em primeiro lugar, busca curiosamente o corpo de sua interlocutora, se aproxima, escuta, olha, toca ... e uma vez iniciada essa relação se dispõe às mais diferentes reações (Lancetti, 2015, p. 63)".

Foi nesse exercício de estranhamentos, afetos, impactos, denominado aqui "atletismo afetivo" que produzimos algumas experiências, tais como a confecção de cartões de sentimentos e amizades que foram trocados entre as moradoras das casas, de desenhos e pinturas a serem expostos em atividade alusiva ao dia 18 de maio no centro da cidade, de uma festa junina com decoração, comidas e músicas planejadas entre todas nós e outras atividades que escapam aos limites deste texto, como, por exemplo, conversas sobre gostos por cores, bichos, sabores, músicas, dentre outras.

Numa ação mais direta com as mulheres cuidadoras trabalhadoras, desenvolvemos e executamos, em parceria com a equipe técnica, uma atividade de formação para elas. Além da participação na confecção dos materiais que seriam utilizados durante a formação, produzimos uma cartilha com o objetivo de discutir sobre o cuidado e sua execução. Para tanto, nos debruçamos sobre o trabalho das cuidadoras no âmbito das residências inclusivas e, nesse sentido, encontramos uma interface importante com o cuidado operado nos serviços residenciais terapêuticos vinculados à política nacional de saúde mental.

Tal como apresentam Amorim e Dimenstein (2009), nos serviços residenciais terapêuticos, o cuidado deve ser pensado a partir de práticas cotidianas, que se atualizam e são geridas conforme a necessidade de seus/suas moradores/as, a fim de promover a singularização do cuidado. Considerando a complexidade da proteção social às moradoras das residências inclusivas, que tinham histórico de internações em instituições manicomiais, a produção da cartilha se amparou na dimensão processual e afetiva do cuidado. Além disso, foram abordados os direitos trabalhistas, visto ser um elemento importante ante às condições de trabalho das cuidadoras. Um dos desafios da produção da cartilha foi utilizar uma linguagem acessível e que produzisse sentido nas práticas cotidianas das trabalhadoras.

Ainda que tal demanda houvesse sido direcionada ao nosso lugar de especialistas, buscamos 
operar com a ideia de que as trabalhadoras produziam suas atividades em experimentação com o campo de atuação, a partir de seus territórios existenciais, o que se refletia no cuidado e na proteção social às moradoras. Concordamos com Franco e Merhy (2013, p. 161) quando argumenta que:

o que define o perfil de cuidado não é o lugar físico onde se realiza o cuidado, mas o território existencial no qual o trabalhador se inscreve como sujeito ético-político, e que anda com ele onde estiver operando seu processo de trabalho (Franco \& Merhy, 2013, p. 161).

A formação buscou, assim, contemplar - cuidado executado pelas cuidadoras como parte dos processos de desinstitucionalização das mulheres moradoras e a ampliação dos seus modos de execução, considerando a complexidade que é produzir cuidado e proteção social em uma casaserviço de mulheres moradoras com histórico de longas internações e violências em instituições de caráter manicomial.

Entendemos que as aproximações iniciais, a convivência semanal, as diferentes atividades desenvolvidas, os medos, os estranhamentos e os impactos compartilhados com as moradoras e cuidadoras foram responsáveis pela possibilidade de produzir a intervenção fotográfica, apresentada a seguir.

\section{A Intervenção Fotográfica: Produção de Processos de Subjetivação e Desinstitucionalização}

Após as aproximações iniciais nos dedicamos à realização de uma intervenção fotográfica com as mulheres moradoras, com o objetivo de produzir processos de desterritorialização através de deslocamentos e registros fotográficos feitos pela cidade. Entendíamos que tais deslocamentos e os registros fotográficos permitiriam tensionar as visibilidades e as invisibilidades produzidas por discursos hegemônicos sobre a deficiência e os transtornos mentais, sobre a institucionalização e a desinstitucionalização, bem como sobre a exclusão social de corpos atravessados pelo gênero, pela deficiência e pelos transtornos mentais.
Propusemos às mulheres que fôssemos a pé até alguns lugares públicos e que, nesse processo, elas pudessem fazer registros fotográficos, com câmeras fotográficas e/ou telefones celulares, 11 delas concordaram. Assim, em um primeiro momento, fizemos uma aproximação com os dispositivos fotográficos para que elas pudessem fazer um uso proveitoso dos mesmos, auxiliando no manuseio da câmera e dos telefones celulares, conforme a necessidade de cada uma. Logo, levando em consideração as indicações das mulheres e dentro das possibilidades - nossas e delas - nos deslocamos a pé até praças públicas próximas às suas casas. Em um dia específico, com o auxílio do motorista das residências, fomos de carro até o ponto turístico da cidade, localizado no alto de uma colina, onde há um monumento à Nossa Senhora das Graças. Ao todo realizamos seis "saídas fotográficas" e, em geral, elas ocorreram de forma intercalada entre as moradoras das duas residências. Saíamos com uma ou mais moradoras ao mesmo tempo, o que dependia das condições e necessidade de cuidado a serem dispensados.

As combinações desse processo foram feitas pouco a pouco entre nós, numa experimentação constante. Entretanto, em determinados momentos, reconhecemos que modos de subjetivação capitalística predominavam, reificando relações de saber-poder assimétricas. Entendemos, por exemplo, que no afã de cumprir com nossos preceitos estéticos, sugerimos ângulos, lugares e mesmo o que poderia vir a ser o nome da exposição e, assim, incorremos de certa maneira no capacitismo (Mello, 2016). A problematização e análise de nossas implicações nesse processo foi uma ferramenta potente para nossa produção subjetiva e formação crítica.

Por sua vez, entendemos que nossa proposta de intervenção fotográfica possibilitou deslocamentos subjetivos e geográficos importantes entre nós. Para além do registro fotográfico em si, todas as etapas produzidas durante a intervenção possibilitaram processos de desterritorilização, ou seja, fomos produzindo e percorrendo linhas de fuga nos processos de territorialização instituídos até então. Desta maneira, concordamos com Coelho (2005), quanto à importância da criação de 
processos de singularização nos quais possam se afirmar as diferenças e se construir modos singulares de existência, escapando às normatizações e individualizações, tais como as que marcaram as trajetórias de vida, nossas e das mulheres moradoras das residências inclusivas.

A saída das casas, o deslocamento em espaços públicos e a proposta de fazer registros fotográficos, que pode parecer uma atividade banal e corriqueira, se configurou como um processo de experimentação na cidade e de autoria e autorização de olhares sobre ela, tal como argumenta Maurente (2009). De início, as mulheres fotografavam a si mesmas, cumprindo com uma estética hegemônica do uso da fotografia como registro do real (Dubois, 1994). Após algumas provocações, feitas por nós, para que se sentissem interpeladas pelas imagens da cidade, passaram a registrar paisagens, lugares e seus detalhes, em uma construção bastante profícua de si mesmas. Segundo Dubois (1994), a fotografia pode ser entendida como um traço do real, remetendo a algo singular que a torna inseparável do ato que a concebe.

Entendemos que nossa provocação para que fotografassem outras paisagens, objetos, detalhes e lugares foi uma estratégia para a saída da representação do real na fotografia, ou seja, uma abertura para a singularização do olhar, uma vez que não nos interessava apenas o produto pronto, a fotografia em si mesma, mas os processos de produção subjetiva desencadeados. 0 processo de construção de si e do mundo presentes nos registros fotográficos produzidos pelas mulheres nos permitiu reconhecer processos de desterritorialização e desinstitucionalização importantes.

A partir do contato com a câmera fotográfica e/ou com o telefone celular, com a ação e criação da fotografia, com o espaço público, com a saída das casas na companhia das estagiárias, de estar e circular na cidade, produzimos outras possibilidades enunciativas enquanto sujeitos. Além disso, foi o encontro com o desconhecido e com as interrogações enquanto experimentações em um campo de embates que permitiu a desnaturalização dos lugares social e historicamente instituídos e o agenciamento de modos outros de se produzir subjetivamente.

Segundo Freitas (2012, p.08), "a fotografia parece contribuir para descobrir ou redescobrir o sentimento de reintegração, reinserção, de pertencimento a algum lugar e de fazer parte de uma história". Corrobora nesse sentido a cena vivida em um dos dias em que fomos até uma das praças com Teresa, uma das moradoras, quando ela quis fotografar um ônibus que estava parado na praça, identificando-o como "o ônibus do CAPS", serviço que ela frequentava e que ofertava o transporte a seus usuários/as. Atentamos para o fato de que ao reconhecer aquele automóvel no espaço público da praça, ela poderia estar se produzindo numa outra relação com a cidade, com as circulações e os pertencimentos possíveis. Vale lembrar que Teresa esteve por muitos anos privada de liberdade em instituições de caráter manicomial e que ir até uma praça pública, utilizar transporte coletivo e registrar seu olhar sobre o mundo pareciam ganhar uma dimensão bastante singularizada no seu processo de desinstitucionalização e de produção subjetiva.

Entendemos que 0 processo de desterritorialização produzido na construção dos registros fotográficos não se deu como uma "adaptação" das mulheres na cidade, mas, pelo contrário, quando as convidamos para olhar e fotografar, fizemos um convite para uma nova reterritorialização, agora enquanto autoras, num processo mais próximo de uma "composição". De acordo com Freitas (2012, p.8), "ao direcionar a câmera fotográfica para algo (um objeto, evento, pessoa, lugar) em resposta a uma pergunta ou temática, na medida em que determinada pessoa capta esta imagem através da fotografia, também mostra algo de si". Nesse sentido, entendemos que nos registros fotográficos produzidos havia algo de singular e que nos parecia contribuir para os processos de subjetivação singulares e também de desinstitucionalização.

A produção de subjetividade, segundo Guattari e Rolnik (1996), ocorre em um todo maquínico, do qual fazem parte as instituições de ensino, a vida doméstica, a família, a mídia, entre outros. Assim, os discursos produzidos e instituídos conformam a trama social onde tais processos ganham visibilidade. Entretanto, a trama está sempre por fazer-se, inventar-se, ou seja, ela vai 
sendo produzida a todo momento por diferentes enunciações dos sujeitos.

Outra cena relevante do processo de registros fotográficos foi vivida com Marta e Sofia. Caminhávamos em uma praça próxima a uma das casas e avistamos a igreja, quando, então, elas foram enfáticas na vontade de fotografá-la. Como mulheres atravessadas pela fé, que frequentavam os rituais católicos, além do registro, naquele momento, produziram narrativas sobre si mesmas, indicando um agenciamento importante com a religiosidade. Esse nos pareceu ser um exemplo importante para pensarmos sobre os agenciamentos possíveis entre enunciações já conhecidas pelas mulheres, como a religião, mas, sobretudo, a relevância da laicidade nos processos de desinstitucionalização.

Desse mesmo dia destacamos outro aspecto. Marta e Sofia, avistaram o motorista responsável pelo transporte das moradoras nas proximidades do escritório de trabalho da equipe técnica das residências e decidiram dirigir-se a ele para saber se as profissionais estavam por lá. Ao saber que elas não estavam, numa espécie de apropriação daquele local, adentraram o prédio, foram até a cozinha e, com as devidas permissões, tomaram café, tiraram fotos de alguns objetos e solicitaram que tirássemos fotos delas ali. Vislumbramos, naquela cena, um campo de afetos produzidos entre as moradoras e a equipe técnica que permitia adentrar esse local bastante socializador que é a cozinha (Simões, 2008).

Após o período das "saídas fotográficas", iniciamos o processo de seleção das fotos e da construção de uma proposta de exposição pública delas. Para tanto, organizamos sessões de apresentação das fotos em um notebook, conversávamos entre nós sobre o que íamos vendo, ou seja, produzindo narrativas sobre as fotografias. Aqui, concordamos com Bruno (2015): as imagens se firmam como "um ato" (e não um objeto), ou seja, elas participam da experiência de tempo e narrativa.

Para a proposta de uma exposição pública das fotos, fizemos um processo parecido. Mostramos diferentes exposições fotográficas através da tela do computador. Para fazermos a escolha "final" das fotos, precisamos reafirmar a importância da autoria das moradoras, visto que em um primeiro momento elas haviam decidido expor os registros fotográficos delas mesmas, feitas por nós. Pensamos que foi tênue a linha que se interpôs entre acatarmos prontamente tal escolha e nos colocarmos como agentes de desterritorialização, para que elas se produzissem como autoras, e nos arriscamos enquanto tal. Assim o foi também com a escolha do título da exposição, elaborado num processo intenso de provocações.

Esse movimento das escolhas nos provocou muitas reflexões. Buscamos compor as ações em conjunto com as mulheres, o que implicou um acordo de ambas as partes. Contudo, como as relações de saber - poder nos situam em posições distintas na trama social, em certos momentos entendemos que nossas sugestões podem ter sido ressentidas como verdades per se ou como mais adequadas que as delas. Nesse sentido, pensamos com Foucault (2004) que, onde existem relações de poder, há liberdade, ou melhor, práticas de liberdade, permeadas por discursos de saber. Assim, o movimento de resistência só foi possível em uma relação produzida com um mínimo de liberdade. Segundo o autor:

nas relações de poder, há necessariamente possibilidade de resistência, pois se não houvesse possibilidade de resistência (de resistência violenta, de fuga, de subterfúgios, de estratégias que revertam a situação), não haveria de forma alguma relações de poder (Foucault, 2004, p. 8).

Pensamos nessas possibilidades de resistência de diferentes maneiras durante a intervenção fotográfica. Quando propusemos a saída das casas para fotografar a cidade, Beatriz, uma das moradoras, disse que queria participar, mas que não sairia. Nos indicando as linhas que conformavam seu território existencial, insistiu em tirar várias fotos do seu cachorro, para o qual dispensava muito carinho. Acatamos sua decisão por entendermos que seu movimento de escapar à norma, de fazer valer sua vontade, de exercício da negociação sobre seus registros fotográficos eram importantes na experimentação proposta, nossa e dela.

Outra moradora, Helena, ainda que tenha participado das "saídas fotográficas", optou por fazer os registros fotográficos no interior da casa, num processo que nos levou a reconhecer como de 
apropriação desta, visto que ela morava ali há pouco tempo. Até então, Helena vivia em uma Instituição de Longa Permanência, ou seja, no âmbito do seu processo de desinstitucionalização, a casa fotografada parecia produzir algo, quiçá de vida, já que havia a oferta de estudar, de fazer compras sozinha, de escolher o que comer, comprar roupas, entre outros, bem como a possibilidade de fotografar.

Quando entramos em acordo com a realização da exposição pública dos registros fotográficos, definimos também os locais públicos onde ela seria realizada e, ante as possibilidades construídas, realizados uma exposição na Câmara Municipal de Vereadores e outro nas dependências da universidade, em períodos distintos. Na universidade, diferente da Câmara Municipal dos Vereadores, foi possível realizar a abertura da exposição com a participação das mulheres moradoras. No momento da abertura, algumas das mulheres moradoras autoras das fotografias conversaram com o público, em sua maioria, estudantes e professoras/es universitárias/os. Considerando a acústica do local de abertura da exposição, fizemos uso do microfone, o qual também foi utilizado pelas moradoras - autoras das fotografias.

Pensando a intervenção enquanto um processo, entendemos que ela produziu movimentos de desterritorialização e reterritorialização subjetivos importantes. A partir dos nossos encontros, do encontro delas com as paisagens da cidade, com os/as demais transeuntes, com os equipamentos fotográficos até a abertura da exposição, houve, tal como aponta Rolnik (2006), um rompimento com os processos de institucionalização dessas mulheres, em processos de desinstitucionalização nos quais foi possível perceber novas territorialidades. Territórios que se reterritorializaram no momento em que elas se autorizaram a produzir um olhar sobre a cidade, a falar em público e a ocupar um espaço outrora distante das possibilidades produzidas pelas instituições à que estavam vinculadas.

Uma cena nos pareceu emblemática da finalização do processo: enquanto fazíamos comentários sobre a intervenção fotográfica na abertura da exposição na universidade, Sofia pediu o microfone e falou ao público que iria se formar no ano seguinte no ensino médio e que, caso conseguisse ingressar na universidade, logo seria colega das pessoas que estavam na plateia. Como afirmam Deleuze e Guattari (1995), o território é antes de tudo um lugar de passagem. Passagem de afeto, de desejo e de devires produzidos nos agenciamentos de outros possíveis, com os quais a psicologia pode contribuir e produzir.

\section{Considerações Finais}

A partir da experiência de estágio apresentada e discutida, foi possível compreendêla como uma ferramenta potente para a nossa formação enquanto futuras profissionais, engajadas com o compromisso ético político da profissão, bem como vislumbrar sua potência enquanto espaço de relações produtoras de processos de subjetivação às mulheres moradoras das residências inclusivas e à nós, conjuntamente.

Salientamos que o estágio foi uma prática que se deu na produção do encontro, ou seja, não estava pronto antes de chegarmos a campo. Produzimos a experiência desde as primeiras aproximações com as mulheres moradoras, com as cuidadoras, com o motorista e com a equipe técnica. Destacamos, sobretudo, a acolhida e disponibilidade que tivemos por parte de toda a equipe técnica que sempre concedeu apoio e autonomia para desenvolvermos as ações.

Entendemos que a intervenção fotográfica permitiu a criação de linhas de fuga e desterritorialização nos processos de desinstitucionalização e produção de subjetividade das mulheres moradoras, provocadas pelos olhares produzidos com a cidade, para as múltiplas conexões que elas já estabeleciam. Produziu-se, assim, novas conexões com esses espaços, ou seja, permitiu narrar o que antes escapava ao olhar, ao pensar e ao sentir (Strappazzon, Santa, Werner, \& Maheirie, 2008), ocupando-os de forma política. Outrossim, permitiu também exercitar o agenciamento da escolha, na relação diária com as práticas de liberdade possíveis ao habitar uma instituição com seus diferentes atores e atravessamentos, fazendo emergir o ato de singularização da própria narrativa enquanto sujeito. 
Para além da intervenção aqui apresentada, salientamos que os dispositivos da assistência social, tais como as residências inclusivas, podem ser locais de reinvenção dos sujeitos que ali moram, vislumbrando a desinstitucionalização e agenciamentos diversos que produzam subjetividades singularizadas, com práticas de liberdade e autonomia.

\section{Contribuição}

As pesquisadoras declaram não haver conflitos de interesse.

\section{Referências}

Amorim, A. K. M. A., \& Dimenstein, M. (2009). Desinstitucionalização em saúde mental e práticas de cuidado no contexto do serviço residencial terapêutico. Ciência \& Saúde Coletiva, 14(1), 195-204. https://www.scielo. $\mathrm{br} / \mathrm{pdf} / \mathrm{csc} / \mathrm{v14n1/a25v14n1.pdf.} \mathrm{https://doi.}$ org/10.1590/S1413-81232009000100025

Baremblitt, G. F. (1996). Compêndio de análise institucional e outras correntes: teoria e prática. Rosa dos tempos.

Bruno, F. (2015). Imagem, sopro de um abismo narrativo. In S. Kofes, \& D. Manica (Org.), Vida e grafias: narrativas antropológicas, entre biografia e etnografia. (pp. 406-408). Lamparina \& FAPERJ.

Coelho, D. A. M. (2005). Práticas clínicas e modos de subjetivação - Reflexões ético-estéticopolíticas. Mnemosine, 1(2), 423-458. https:// www.e-publicacoes.uerj.br/index.php/ mnemosine/article/view/41393/pdf_62

Constituição da República Federativa do Brasil de 1988. http://www.planalto.gov.br/ccivil_03/ constituicao/constituicao.htm

Deleuze, G. \& Guattari, F. (1995). Mil Platôs: capitalismo e esquizofrenia (Vol. 1, A. G. Neto, \& C. P. Costa, Trad.). Editora 34.
Dubois, P. (1998). O ato fotográfico e outros ensaios ( 2 a ed.) (Mariana Appenzeller, Trad.). Campinas: Papirus.

Foucault, M. (2004). A ética do cuidado de si como prática da liberdade. In M. Foucault, Ditos \& Escritos (Vol. 5 - Ética, Sexualidade, Política). Forense Universitária.

Franco, T. B. \& Merhy, E. E. (2013). O reconhecimento de uma produção subjetiva do cuidado. In T. B. Franco \& E. E. Merhy (Org.), Trabalho, produção do cuidado e subjetividade em saúde (pp. 151-171). Hucitec.

Freitas, A. C. H. (2012). A fotografia como recurso terapêutico em um CAPS: a possibilidade de novos olhares [Trabalho de conclusão de curso, Grupo Hospitalar Conceição/ Residência Integrada em Saúde].

Gomes, R. B., Lopes, P. H., Gesser, M. \& Toneli, M. J. F. (2019). Novos diálogos dos estudos feministas da deficiência. Estudos Feministas, 27(1), e. 48155. https://www.scielo.br/pdf/ ref/v27n1/1806-9584-ref-27-01-e48155. pdf. https://doi.org/10.1590/1806-95842019v27n148155

Guattari, F., \& Rolnik., S. (1996). Micropolítica: cartografias do desejo ( $4^{\mathrm{a}}$ ed.). Vozes.

Hess, R. (2006). O momento do diário, o diário dos momentos. In E. C. Souza \& M. H. M. B. Abrahão (Org.). Tempos, narrativas e ficções: a invenção de si (pp. 89-104) EDIPUCRS.

Knevitz, A. G. (2016). Trabalhadores na assistência social. In: R. M. C. Fernandes, A. Hellmann (Org.). Dicionário Crítico: política de assistência social no Brasil (pp. 279-282). Editora da UFRGS.

Lancetti, A. (2015). Contrafissura e Plasticidade Psíquica. Hucitec.

Lei no 4.119, de 27 de agosto de 1962. (1962, 5 setembro). Dispõe sobre os cursos de formação em psicologia e regulamenta a profissão de psicólogo. Presidência da República. http://www. planalto.gov.br/ccivil_03/leis/1950-1969/14119. htm\#: :text=Disp\%C3\%B5e\%20s\%C3\%B4bre\%20 os $\% 20$ cursos $\% 20$ de, regulamenta $\% 20$ a\%20profiss\%C3\%A3o\%20de\%20 psic\%C3\%B3logo.\&text=Art.\&text=\%C2\%A7\%20 1\% C 2\%BA\%20A o\%20aluno\%20que,diploma\%20 de\%20Licenciado\%20em\%20Psicologia 
Lei no 8.742, de 7 de dezembro de 1993. (1993, 8 dezembro). Dispõe sobre a organização da Assistência Social e dá outras providências. Presidência da República. http://www.mds.gov. br/webarquivos/publicacao/assistencia_social/ Normativas/LoasAnotada

Lei n. 11.788 de 25 de setembro de 2008. (2008, 25 setembro). Dispõe sobre o estágio de estudantes; altera a redação do art. 428 da Consolidação das Leis do Trabalho - CLT, aprovada pelo Decreto-Lei no 5.452, de 1o de maio de 1943, e a Lei no 9.394, de 20 de dezembro de 1996; revoga as Leis nos 6.494, de 7 de dezembro de 1977, e 8.859, de 23 de março de 1994, o parágrafo único do art. 82 da Lei no 9.394, de 20 de dezembro de 1996, e 0 art. 6으 da Medida Provisória ำ 2.164-41, de 24 de agosto de 2001; e dá outras providências. http://www.planalto.gov.br/ccivil_03/_ato20072010/2008/lei/I11788.htm

Lei n. 13146 de 6 de julho de 2015. (2015, 7 julho). Dispõe sobre a Lei Brasileira de Inclusão da Pessoa com Deficiência (Estatuto da Pessoa com Deficiência). Presidência da República. http:// www.planalto.gov.br/ccivil_03/_ato 20152018/2015/lei/l13146.htm

Maurente, V. (2009). Ver, conhecer e pensar por caminhos fotográficos. In J. Tittoni, (Org.). Psicologia e Fotografia: experiências em intervenções fotográficas (pp. 46-55). Dom Quixote.

Mello, A. G. de. (2016). Deficiência, incapacidade e vulnerabilidade: do capacitismo ou a preeminência capacitista e biomédica do Comitê de Ética em Pesquisa da UFSC. Ciência \& saúde coletiva, 21(10), 3265-3276. http://www. scielo.br/scielo.php?script=sci_arttext\&pid= S1413-81232 016001003265\&lng=en\&nrm=iso. https://doi.org/10.1590/ 1413812320152110.07792016 .

Medrado, B., Spink, M. J., \& Méllo, R. P. (2014). Diários como atuantes em nossas pesquisas: narrativas ficcionais implicadas. In M. J. P. Spink, J. I. M. Brigagão, V. L. V. do Nascimento \& M. P. Cordeiro (Orgs.). A produção de informação na pesquisa social: compartilhando ferramentas (Cap. 13, pp. 273-294). Centro Edelstein de Pesquisas Sociais. (Publicação virtual).
Ministério do Desenvolvimento Social e Combate à Fome. (2014) Residências Inclusivas: perguntas e respostas. https://fpabramo. org.br/acervosocial/wp-content/uploads/ sites/7/2017/08/138.pdf

Motta, R. F., \& Scarparo, H. B. K. (2013). A Psicologia na assistência social: transitar, travessia. Psicologia \& Sociedade, 25(1), 230-239. https:// www.scielo.br/pdf/psoc/v25n1/25.pdf

Resolução $n^{\circ}$ 17, de 20 de junho de 2011. Ratifica a equipe de referência definida pela Norma Operacional Básica de Recursos Humanos do Sistema Único de Assistência Social NOB-RH/SUAS e Reconhecer as categorias profissionais de nível superior para atender as especificidades dos serviços socioassistenciais e das funções essenciais de gestão do Sistema Único de Assistência Social - SUAS. https:// www.sigas.pe.gov.br/files/07252018113943cnas.n.17.de.20.de.junho.de.2011.pdf

Resolução no 109 de 11 de novembro de 2009. Aprova a Tipificação Nacional de Serviços Socioassistenciais. Recuperado de https:// www.mds.gov.br/webarquivos/ public/ resolucao_CNAS_N109_\%202009.pdf.

Rolnik, S. (2006). Cartografia Sentimental. Ed. da UFRGS.

Secretaria dos Direitos Humanos \& Secretaria Nacional de promoção dos direitos da pessoa com Deficiência. (2013). Viver Sem Limites: Plano nacional dos Direitos da Pessoa com Deficiência (4 ${ }^{\mathrm{a}}$ ed.). Brasília.

Simões, S. S. (2008). Cuidar do Ser: sociabilidade feminina e hermenêutica em um conjunto habitacional da Zona Sul do Rio de Janeiro. Revista Comum 14(31), 144-159.

Strappazzon, A. Santa, B., Werner, F. W. \& Maheirie, K. (2008). A criação fotográfica e o aumento da potência de ação: experiências e possibilidades. Cadernos de psicopedagogia. 7(12). http:// pepsic.bvsalud.org/scielo.php?script=sci arttext\&pid=S1676-10492008000100002\&lng= pt\&nrm=iso 